\title{
Cognitive Dissonance, Pessimism, and Behavioral Spillover Effects ${ }^{*}$
}

\author{
David L. Dickinson ${ }^{\dagger}$ \\ Dept. of Economics \\ Appalachian State University
}

\author{
Robert J. Oxoby ${ }^{\ddagger}$ \\ Dept. of Economics \\ University of Calgary
}

\begin{abstract}
This paper reports results from a unique two-stage experiment designed to examine the spillover effects of optimism and pessimism. In stage 1, we induce optimism or pessimism onto subjects by randomly assigning a high or low piece rate for performing a cognitive task. We find that participants receiving the low piece rate are significantly more pessimistic with respect to performance on this task. In stage 2 individuals participate in an ultimatum game. We find that minimum acceptable offers are significantly lower for pessimistic subjects, though this pessimism was generated in a completely unrelated environment. These results highlight the existence of important spillover effects that can be behaviorally and economically important - for example, pessimism regarding one's initial conditions (e.g., living in poverty) may have spillover effects on one's future labor market outcomes.
\end{abstract}

JEL Codes: C91, D84

Keywords: optimism, pessimism, bargaining, experiments

\footnotetext{
${ }^{*}$ We thank Kendra McLeish for research assistance. Financial support was provided by the Social Science and Humanities Research Council of Canada and the Institute for Advanced Policy Research

${ }^{\dagger}$ Department of Economics, Appalachian State University, Boone, NC USA 28608. Phone: 828-262-7652. Fax: 828-262-6105. e-mail: dickinsondl@appstate.edu.

${ }^{\ddagger}$ Department of Economics, University of Calgary, Calgary AB Canada T2N1N4. Phone 403-220-2586. Fax 403282-5262. e-mail: oxoby@ucalgary.ca.
} 


\section{MOTIVATION}

Individuals’ expectations play an important role in most decision environments. As such, the presence of any bias in subjective expectations can affect many economic outcomes. Two of the most common types of biases affecting expectations (and hence outcomes) are the tendencies for optimism and pessimism in individuals’ beliefs and attitudes. Optimism or “overconfidence”, for example, can take on many forms (see Babcock and Loewenstein, 1997; Rabin, 1998). Overconfidence may increase the likelihood of dispute in a bargaining environment (Babcock and Loewenstein, 1997; Dickinson, 2006), affect the manner in which individuals make financial decisions (Barber and Odean, 2001; Odean, 1998), or increase the likelihood of careless decisions if the over-confidence is with respect to one’s driving skills (Svenson, 1981) or one's health (Weinstein, 1980). Though some psychology research explores pessimism (e.g., in depressed individuals: see Pyszczynski et al., 1987), much of the research in both psychology and economics has focused on optimism and self-serving beliefs. However, it is important to note than in many circumstances overconfidence in one domain implies pessimism in another: overconfidence in the information one receives (as in Rabin and Schrag, 1999) or in the advice received from others (as in Rabin, 2002) implies pessimism in one’s own private information and relative abilities. Experimentally, Heolzl and Rustichini (2005) studied the effect of optimism in one's relative ability in a skill task. While individuals are optimistic in their own abilities, results suggest that pessimism is more prevalent when facing more difficult tasks, especially when money is at stake.

This present paper examines expectations in a unique environment in which we explore first how optimism and pessimism can be induced and, secondly, how optimism and pessimism in one area can affect behavioral outcomes in another. We begin by examining laboratory 
induced beliefs with respect to one's own performance in a letter-ordering task. We find that optimism/pessimism can be induced via the ex post random assignment of a high or low piecerate wage for performing this cognitive task. We observe significantly more pessimism (i.e., expected output less than actual output) among subjects who are randomly assigned a low piecerate wage. The opposite occurs (i.e., optimism) for subjects paid the high piece-rate wage. Our ability to induce optimism or pessimism in this environment can be explained by theories of cognitive dissonance (e.g., Aronson 1992), where the generation of an optimistic or pessimistic belief can reduce an inherent conflict between cognitions. We then conduct a second stage experiment in which these same subjects engage in a simple bargaining (ultimatum) game.

Our results highlight two important conclusions: First, consistent with cognitive dissonance theories, we are able to induce optimism or pessimism with the initial (random) wage assignment. With respect to the first-stage task, this implies that we can successfully manipulate one's ability-beliefs in the lab. Secondly, subjects who received this low piece-rate in stage one were willing to accept significantly lower offers in a second-stage ultimatum game. This finding is striking, demonstrating the presence of both belief manipulation and spillovers of those beliefs into behavioral outcomes in an unrelated and distinct experimental environment.

There is increasing evidence in the psychology literature that one’s beliefs regarding future outcomes (so-called “dispositional optimism-pessimism”) are a dimension of personality that affects life-choices and outcomes (Heinonen, et al., 2005). The important implication is that optimism-pessimism in one environment may not be independent from optimism-pessimism in another. For example, if dispositional pessimism at one point in time can significantly predict one's tendency to be passive or withdraw effort (Scheier and Carver, 1985), and if such a disposition is persistent and stable, then an event that affects one's disposition will have spillover 
effects with potentially important economic consequences (e.g., job search, bargaining behavior, investment choice, etc.). For example, Goldsmith et al (1997) shows that one’s "psychological capital” significantly affects labor market earnings. Specifically, an investment in one’s psychological capital is estimated to increase wages by even more than a comparable investment in human capital. Thus, whatever initially contributes to an individual's stock of psychological capital has important spillovers into measurable labor market outcomes.

The presence of dispositional optimism and pessimism can be directly related to emotions and self-esteem. For example, a recent review in psychology concludes that positive emotions are a causal factor in successful life outcomes of various sorts (Lyubomirky and King, 2005). While separable from positive emotion or affect, Lucas et al. (1996) find that optimism is related to positive affect. This type of result conforms with those of Charness and Levin (2005) who find that “emotional reinforcement” induced by payment can explain deviations from Bayesian updating. From the standpoint of Lucas et al. (1996), this suggests that the affect created by emotional reinforcement affects the optimism and pessimism individuals may have in their decisions, leading to non-Bayesian behaviors. Generalizing, this literature suggests that optimism and pessimism may play causal roles in many outcomes which have significant longitudinal or experimental effects, such as work absenteeism, marital well-being, charitable giving, and judgment accuracy, among others (see Lyunbomirky and King, 2005).

In terms of self-esteem, psychologists consider certain events or environments can ascribe self-esteem (Lane, 1991; Glietman, 1991), which relates to dispositional optimismpessimism. Here, we utilize a laboratory manipulation to ascribe a type of optimism-pessimism. Self-esteem and dispositional optimism-pessimism are considered clear contributors to one's outlook and outcomes in life (Scheier and Carver, 1985; Lyunbomirky and King, 2005), and we 
are able to recreate a useful microcosm of this relationship in a simple lab environment where beliefs spill over into separate but meaningful behavioral differences that can have economically significant consequences.

\section{EXPERIMENTS}

We conducted experiments to explore the factors inducing optimism and pessimism and the associated spillover effects of induced optimism and pessimism in a simple bargaining context (i.e. the ultimatum game).

\section{Experiment 1}

In experiment 1 , participants took part in a grammatical reasoning task (i.e., a modified version of the task in Baddeley, 1968). In this task, participants were given a short sentence describing the ordering of either three or four alphabetic letters. These sentences were displayed individually for three seconds, with five seconds between each sentence. After observing a sentence for three seconds, participants wrote down the proper ordering of the letters as described in the sentence. For example, if an individual encountered the sentence "A is followed by $\mathrm{D}$ is followed by B is preceded by $\mathrm{C}$ " she would have to write down CADB to have correctly ordered the letters in accord with the sentence. Similarly, if the participant encountered the sentence "Z does not proceed X does not follow Y," she would have to write down XZY to have correctly ordered the letters. ${ }^{1}$ A total of 64 letter ordering sentences were displayed to participants.

Prior to undertaking the task, participants were informed of the incentives they faced in the experiment. Specifically, participants were informed that they would either be paid $\$ 0.25$ or

\footnotetext{
${ }^{1}$ Instructions describing the rules to be used when ordering letters provided in the appendix and are such that there is a unique letter-ordering to each sentence when using the rule given to subjects.
} 
$\$ 1.25$ for each correct letter ordering on their answer sheet and that the piece rate would only be revealed after the task was completed. That is, participants did not know which piece rate applied at the time they undertook the task.

After the grammatical reasoning portion of the experiment, participants' answer sheets were collected by the experimenter and participants were informed regarding which piece rate would apply (i.e., $\$ 0.25$ or $\$ 1.25$ ). After learning which rate applied, participants were asked two questions. First, participants were asked to indicate a scale of 1 to 10 how much they enjoyed the task. Secondly, participants were asked to estimate the number of questions they answered correctly, receiving an additional $\$ 5$ payment if their estimate was correct and an additional $\$ 3$ payment if their estimate was within two of the actual number of correct answers. ${ }^{2}$

\section{Hypotheses}

With regard to experiment 1 , we put forth two hypotheses. First, with respect to the task enjoyment question, we hypothesize that individuals receiving the lower piece rate (i.e. $\$ 0.25$ ) will report higher levels of enjoyment than those receiving the higher piece rate (i.e. \$1.25). This follows the previous literature on cognitive dissonance (e.g., Aronson, 1992, 1994; Festinger, 1957) and particularly the experiments of Festinger and Carlsmith (1959). In these experiments individuals participating in a mundane task were paid either $\$ 1$ or $\$ 20$ to claim to another individual that the task was enjoyable. Surprisingly, individuals who were paid less for intimating the task as enjoyable reported greater levels of task enjoyment. According to the theory of cognitive dissonance, individuals who were paid less were in a greater state of dissonance (i.e., conflict between the cognitions "I was paid $\$ 1$ to tell someone the task was interesting,” and "I found the task boring.”) and hence reduced dissonance by altering their

\footnotetext{
${ }^{2}$ The displaying of sentences and the enjoyment and expectations questions were programmed using z-Tree (Fischbacher, 2007). Participants responses to the sentences were written down on an answer sheet provided by experimenter and scored manually.
} 
perceived enjoyment of the task; individuals receiving \$20 had less dissonance as the compensation provided a rationale for communicating the task was enjoyable. ${ }^{3}$

According to the theory of cognitive dissonance, an individual experiences dissonance when her actions and cognitions are in conflict. In some instances, it may prove easier to change one's cognitions (e.g., enjoyment of a mundane task) than changing one's actions. In our experiments, participants experience a conflict between the cognitions "I engaged in a boring task" (here, ordering letter sequences) and "I was paid $\$ X$ for engaging in the task." In our experiments, participants receiving the high piece rate have an extrinsic reason for having exerted effort or participated in the task. These individuals are therefore less likely to experience dissonance in the experiment. On the other hand, those participants who received the low piece rate have a much weaker extrinsic reason for having participated. As such, these individuals are in a state of dissonance and look for an intrinsic rationalization for having participated, namely greater enjoyment of the task. Hence we have the following:

H1.1 Individuals who learn (ex post) that they have received the lower piece rate will express higher levels of enjoyment for the task than did those who received the higher piece rate.

Our second hypothesis focuses on individuals' expectations regarding performance. Based on the logic above, individuals who receive the low piece rate are in a state of dissonance relative to those who received the higher piece rate. In addition to reducing dissonance via greater subjective task enjoyment, these individuals may adjust their beliefs regarding their ability in the task to reduce dissonance. Given the conflict between the cognitions described above, Beauvois and Joule (1996) argue that incorporating additional cognitions (as opposed to

\footnotetext{
${ }^{3}$ Similar effects are documented in Aronson and Carlsmith (1963), Aronson and Mills (1959), Axsom and Cooper (1985), and Cooper and Worchel (1970). For a review of the theory of cognitive dissonance (and the various theories falling under its umbrella), see Aronson (1992) and the subsequent commentaries.
} 
changing cognitions) is a mechanism to reduce dissonance. ${ }^{4}$ Within this framework, an individual may incorporate cognitions related to her ability to reduce dissonance, thereby providing additional rationalization for the effort they exerted in the task.

With respect to our experiment, individuals receiving the low piece rate are be in a state of dissonance given the conflict between the cognitions "I exerted effort to earn a large sum of money," and "I received the low piece rate." Incorporating the cognition "I'm not good at this task” reduces the difference between an individual's expected payout under the high piece rate and their payout to the low piece rate. Incorporating the latter cognition implies that individuals receiving the low piece rate will be pessimistic in their abilities, thereby reducing the dissonance created by having exerted effort only to receive a low return (i.e., low piece rate) to their effort. On the other hand, individuals who received a high piece rate do not experience the same character of dissonance. As a result, these individuals are more likely to be unbiased or optimistic regarding their performance on the task. Thus, we have the following hypotheses:

H1.2 Individuals who learn (ex post) that they have received the lower piece rate will be pessimistic in their abilities.

H1.3 Individuals who learn (ex post) that they have received the high piece rate will be optimistic in their abilities.

\section{RESULTS}

Table 1 presents the average scores and expectations for participants receiving the high (\$1.25) and low (\$0.25) piece rates. We identify no differences between scores or expected scores across piece rates (Wilcoxon $p=0.582$ and $p=0.944$ ). However, in line with theories and experiments in cognitive dissonance, we do identify a difference between the subjective level of

\footnotetext{
${ }^{4}$ This approach is based on the idea of a "dissonance ratio" measured as the number of dissonant cognitions divided by the sum of dissonant and consonant cognitions. This formulation was originally suggested by Festinger (1957) and is advocated by Beauvois and Joule (1996).
} 
enjoyment (rated on a scale from 1 to 10) across participants receiving different piece rates (Wilcoxon $p=0.053$ ). This suggests that the experimental manipulation fostered dissonance in participants receiving the low rate. These individuals reduced dissonance by (retrospectively) enjoying the task more.

\begin{tabular}{cccc}
\hline & Score & Expected Score & Enjoyment \\
\hline $\begin{array}{c}\$ 1.25 \text { Piece Rate } \\
(\mathrm{n}=39)\end{array}$ & $39.67(16.95)$ & $41.36(15.66)$ & $4.62(2.33)$ \\
\hline $\begin{array}{c}\mathbf{\$} 0.25 \text { Piece Rate } \\
(\mathrm{n}=50)\end{array}$ & $41.96(16.21)$ & $40.60(16.86)$ & $5.66(2.61)$ \\
& & &
\end{tabular}

Table 1: Mean (st. dev.) of scores, expectations, and subjective enjoyment in Experiment 1.

To measure optimism and pessimism, we calculate the difference between a participant's expectation and score. This difference is positive for optimistic participants and negative for pessimistic participants. Figure 1 presents the distributions of these differences by piece rate. For those participants receiving the high piece rate the mean difference is 1.69 ( $\sigma=11.47$ ); for those participants receiving the low piece rate the mean difference is -1.36 ( $\sigma=11.61)$. Nonparametric Wilcoxon tests reject the hypothesis that the samples are drawn from the same distribution ( $p=0.0581$ ), suggesting that participants receiving the higher piece rate were more optimistic (or less pessimistic) than those receiving the lower piece rate. 


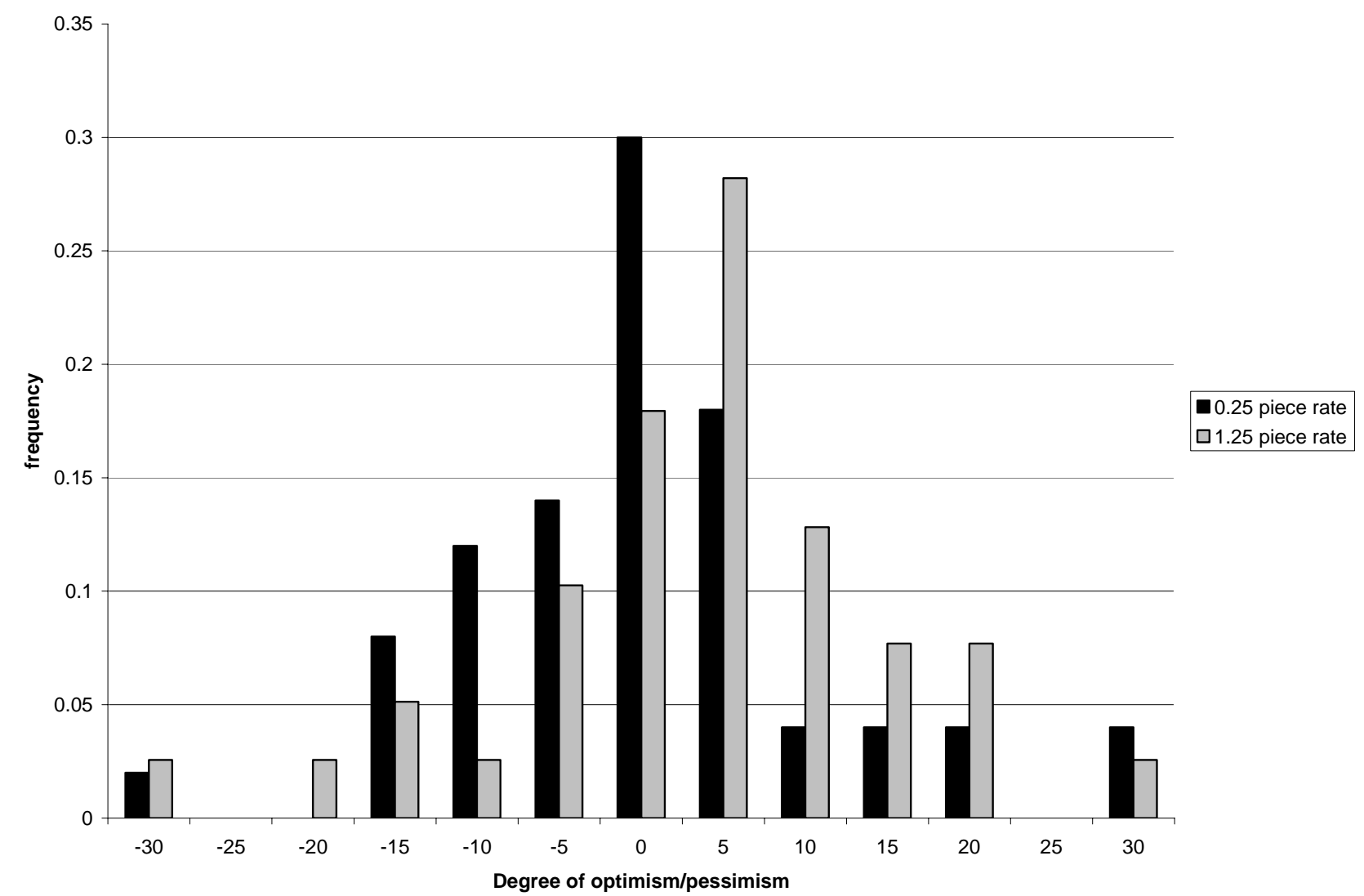

Figure 1: Distributions of degree of optimism/pessimism (i.e., difference between score and expected score) by piece rate in Experiment 1.

\section{Experiment 2}

In our second experiment we explore the spillover effects of induced optimismpessimism on economic behavior in a simple bargaining setting. In experiment 2 individuals participated in the grammatical reasoning experiment described above. Following the grammatical reasoning stage, individuals participated in a simple $\$ 10$ ultimatum game using the strategy method as employed by Oxoby and McLeish (2004) in which the ultimatum game is portrayed as an extensive form game in which (i) nature chooses each player's role, (ii) the proposer chooses her offer and (iii) the responder accepts or rejects. . In the context of our experiment, individuals were described the ultimatum game (in the initial instructions) and were 
asked to enter an offer (to be implemented were they assigned the role of proposer) and enter accept/reject decisions for each possible offer they could receive (to be implemented if assigned the role of responder). ${ }^{5}$ This enables us to calculate for each participant an offer and a minimum acceptable offer.

After all participants entered this information, individuals were paired and randomly assigned the role of either proposer or responder. Given these assignments, the respective offer and accept/reject decisions were implemented. Note that in the ultimatum game portion of the experiment participants were randomly paired and did not know the piece rate that had been paid to the individual with whom they were matched. As such, individuals (if they were conscious of the effect of piece rates on beliefs) did not know whether they were matched with an optimistic or pessimistic participant. Payoffs from the grammatical reasoning and the ultimatum game stages of experiment were paid privately at the end of experiment.

\section{Hypotheses}

We put forth two hypotheses regarding the effects of optimism and pessimism in ultimatum bargaining. Our first hypothesis is in regards to the effect of optimism or pessimism on offers in the ultimatum game.

H2.1 Optimistic (pessimistic) individuals extend lower (higher) offers in the ultimatum game than pessimistic (optimistic) individuals.

This hypothesis follows previous experiments exploring the effects of affective state on behavior economic decision making (e.g., Capra, 2004; Hillman et al, 2004; McLeish and Oxoby, 2007). Similarly, with respect to minimum acceptable offers (MAO) we expect pessimistic individuals to be willing to accept lower offers.

\footnotetext{
${ }^{5}$ Previous research has demonstrated that this method of eliciting decisions in the ultimatum game does not affect the character of play in the ultimatum game. See Oxoby and McLeish (2004) for a discussion of this literature.
} 
H2.2 Pessimistic (optimistic) individuals put forth lower (higher) minimum acceptable offers in the ultimatum game than optimistic (pessimistic) individuals.

\section{Results}

Table 2 presents the summary statistics from Experiment 2. As in Experiment 1, we find no differences in performance on the grammatical reasoning task or expectations across piece rates (Wilcoxon $p>0.50$ for each). However, we do identify differences in the distribution of optimism/pessimism as measured by the differences between expected and actual performance (see Figure 2): Wilcoxon $p=0.052$ between those receiving the high piece rate (mean 4.03 , $\sigma=9.78$ ) and those receiving the low piece rate (mean $-0.18, \sigma=12.15$ ) suggesting results comparable with the results of our experiment 1 . Also, as in experiment 1 , we identify differences between the distributions of elicited enjoyment across piece rates differ $(p=0.058)$, in the direction predicted by the cognitive dissonance hypothesis.

\begin{tabular}{cccccc}
\hline & Score & Expected Score & Enjoyment & Offer & MAO \\
\hline $\begin{array}{c}\text { \$1.25 Piece Rate } \\
(\mathrm{n}=44)\end{array}$ & 37.71 & 41.73 & 5.10 & 4.43 & 3.34 \\
& $(17.11)$ & $(18.37)$ & $(2.25)$ & $(1.09)$ & $(1.35)$ \\
& & & & & \\
$\begin{array}{c}\$ 0.25 \text { Piece Rate } \\
(\mathrm{n}=42)\end{array}$ & 40.27 & 40.09 & 5.84 & 4.45 & 2.59 \\
& $(15.46)$ & $(15.43)$ & $(1.98)$ & $(0.95)$ & $(1.55)$ \\
\hline
\end{tabular}

Table 2: Summary statistics for Experiment 2. 


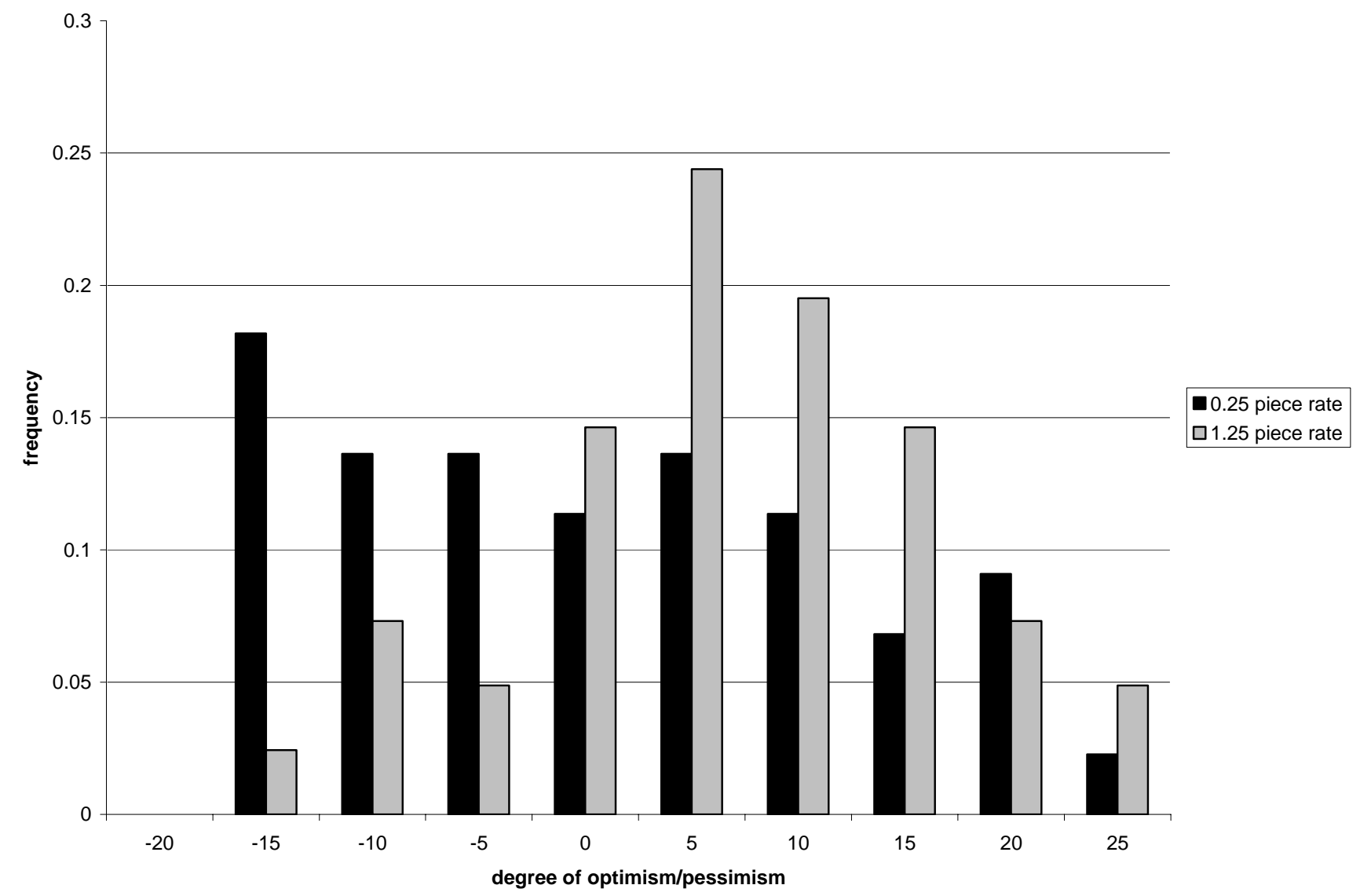

Figure 2: Distributions of degree of optimism/pessimism (i.e., difference between score and expected score) by piece rate in Experiment 2.

With respect to behavior in the ultimatum game, we identify no differences in the offers across piece rate groups (Wilcoxon $p=0.94$ ) and thereby reject hypothesis H2.1. However, we do identify differences in the minimum acceptable offers across each group: Individuals receiving the low piece rate (who were consequently pessimistic) were willing to accept lower offers than those receiving the high piece rate (who were optimistic). These differences are significant (Wilconxon $p=0.025$ ) and we are able to reject the hypothesis that the distributions of MAO by piece rate are drawn from the same population. The distributions of MAO are presented in Figure 3. 


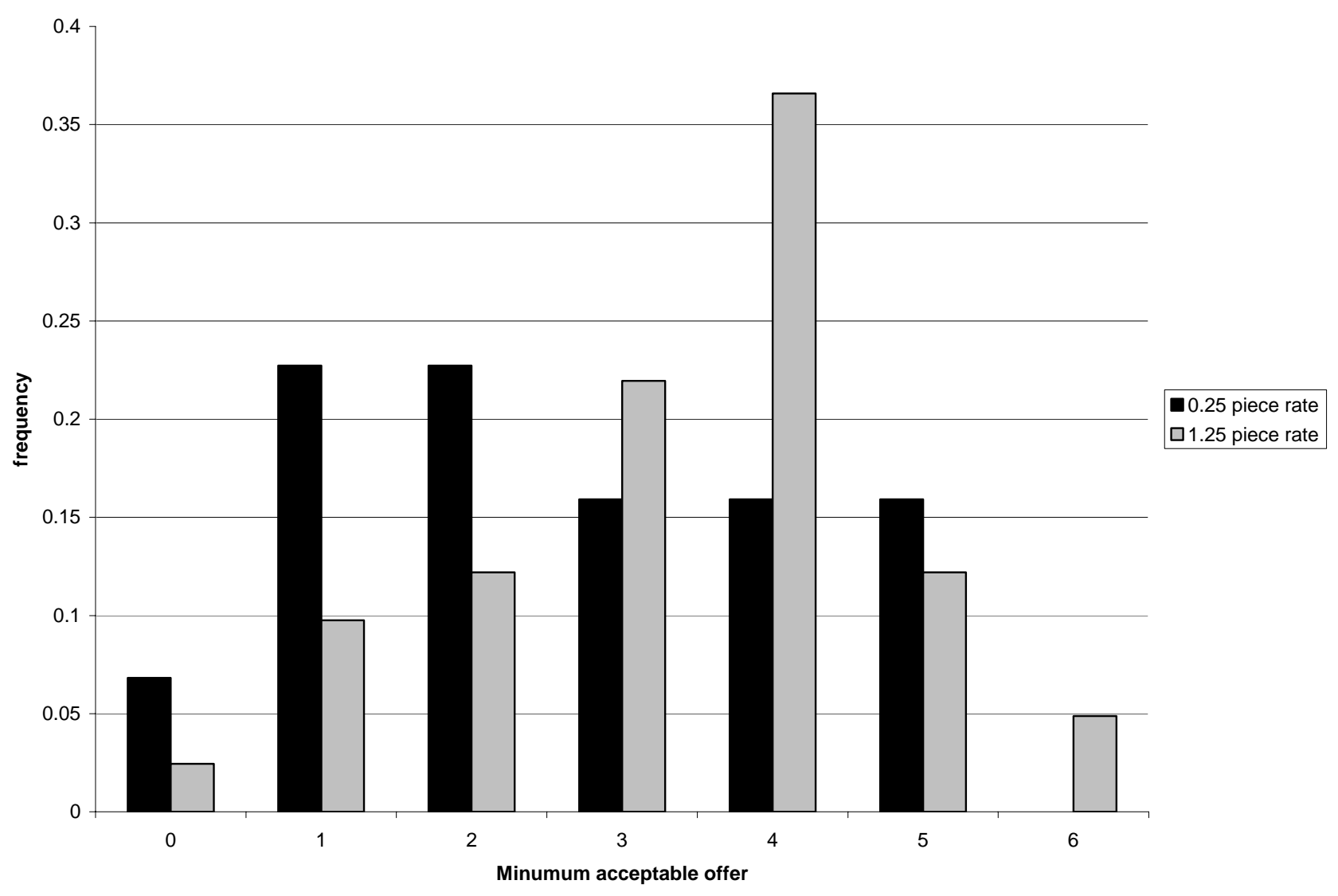

Figure 3: Distributions of minimum acceptable offers by piece rate in Experiment 2.

Moreover, we identify a direct effect of the degree of optimism/pessimism on minimum acceptable offers. Specifically, we regress MAO on the degree of optimism/pessimism and piece rates, identifying separate coefficients for each piece rate. That is we estimate

$$
M A O=\beta_{1} \times O P\left(1-I_{1.25}\right)+\beta_{2} \times O P \times I_{1.25}+\beta_{3} \times P R\left(1-I_{1.25}\right)+\beta_{4} \times P R \times I_{1.25}+\varepsilon .
$$

Where $O P$ is the degree of optimism/pessimism, $P R$ is the piece rate a participant received, and $I_{1.25}$ is an indicator variable picking on the value of one in the participant received a piece rate of a \$1.25 and zero otherwise. This allows us to estimate separate effects of optimism/pessimism across the treatment variable. We find no difference across piece rates regarding the effect of optimism/pessimism on MAO ( $\beta_{1} \approx \beta_{2} \approx 0.026, F(1,81)=0.02$ comparing these coefficients). 
However, pooling the data (i.e., eliminating the $I_{1.25}$ dummy variable) we find that the degree of optimism/pessimism has a small positive effect on MAO ( $\beta=0.026, p=0.068)$, suggesting that an individual's MAO increases by $\$ 0.50$ with a 20 point difference between expected and actual performance. Relative to the typical ultimatum offer of between $\$ 3$ and $\$ 4$ (e.g., see discussion in Camerer, 2003, chapter 2, and Holt, 2007, chapter 12), this effect implies a 10\%-20\% difference in one's MAO resulting from this level of induced optimism/pessimism. The largest effect of MAO is due to the piece rate. We find $\beta_{3}=2.58(p<0.01)$ and $\beta_{4}=10.38 \quad(p<0.01)$, and that these coefficients are significantly different from one another $(F(1,81)=75.38)$. Figure 4 presents the scatterplot of MAO against our measure of optimism/pessimism. These results suggest that the effect of the piece rate on MAO is in some sense discrete: Inducing pessimism in individuals results in substantially lower MAO among participants. This is in accord with our hypothesis 2.2 


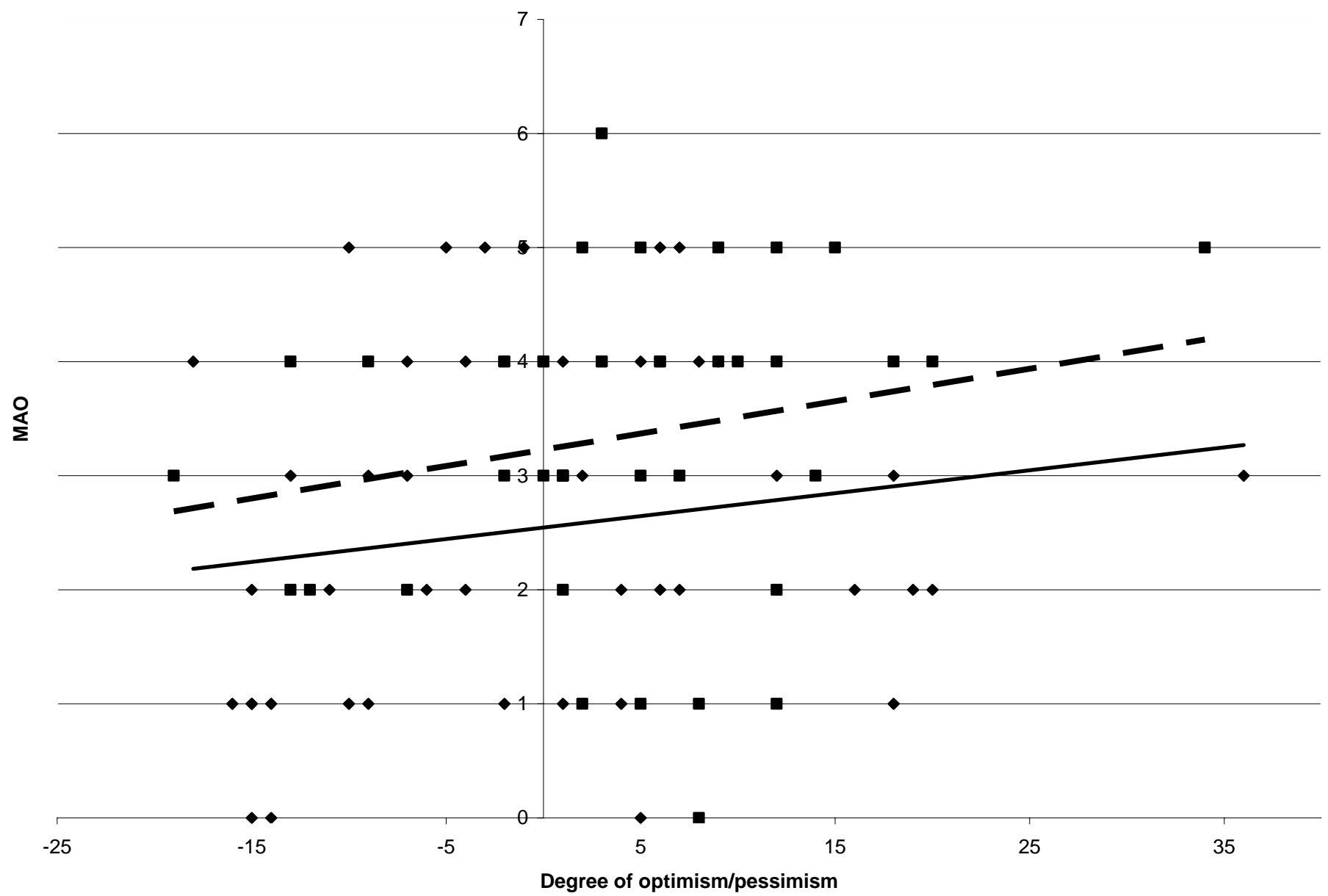

Figure 4: MAO plotted against optimism measure: $\$ 0.25$ piece rate given by solid line and diamonds; $\$ 1.25$ piece rate given by dashed line and squares.

\section{DISCUSSION}

Our key results highlight the interdependence of psychological and behavioral phenomena. Beliefs that were manipulated in a stage 1 experiment significantly affect one's minimum acceptable offer in a stage 2 ultimatum game. Though these data do not consider the robustness of these belief spillover effects into diverse types of environments, they have important implications. While methodologically generating a simple outcome measure, the ultimatum game is a building block of many more complicated environments and is inherent in 
many economic and social interactions. Our results demonstrate that pessimism (in an unrelated environment) negatively affects what an individual is willing to accept or views as fair in a simple bargaining environment (cf. Konow, 2000), suggesting that individuals experiencing pessimism view fair offers (and potentially their own deservingness of monies in the experiment) below those of other individuals.

This result can help explain asymmetries in economic outcomes, such as one's labor market outcomes. Outside the laboratory setting, pessimism about oneself or one's future prospects may emerge from poor initial conditions (e.g. living in poverty) and may have subsequent effects in other domains of life. For example, Oxoby (2004) and Montgomery (1994) argue that individuals with low financial endowments experience dissonance regarding their adherence to mainstream norms. As a result, individuals living in poverty may be more likely to withdraw effort from the labor market and support from their families. Indeed this character of pessimism or dissonance is inherent in the Council of Europe's proposed policies to combat social exclusion (see Avramov, 2002, and Council of Europe, 2001). Pessimism of this sort may manifest itself in lower starting wages or lower and more infrequent wage increases and promotions, both of which may lead to an inferior wage path for pessimistic labor market participants. The inferior wage path would lead to lower relative wages and greater pessimism or lower self-esteem (see Goldsmith, et al., 1997), thereby reinforcing the cycle. As such, combating pessimism can be seen as an important aspect in reducing poverty and reducing social and economic exclusion. The implications of understanding spillover effects of optimism/pessimism may well extend to a host of other important environments, such as marital success, judgment accuracy, or accident rates (Lyubomirsky and King, 2005). 
Methodologically, our first result demonstrates that optimism-pessimism can be manipulated in the lab. The primary importance of this result is that we can then examine laboratory-induced beliefs that are orthogonal to one's general psychological capital, because the low versus high piece rates were assigned randomly to subjects. We exploit the attitudinal responses to cognitive dissonance to generate this initial result and believe that this approach has applicability beyond our experiments. In other words, our experimental methodology highlights how events can ascribe beliefs, for good or bad, which implies that one's optimism or pessimism is built and rebuilt on a constant basis. So, even dispositionally pessimistic individuals can be ascribed optimism that may be reinforced through spillover effects. ${ }^{6}$

Of course, this research has its limitations. First, it is unclear whether different types of beliefs carry more or less importance when spillover effects exist. Perhaps pessimism with respect to one's relative abilities on a cognitive task would have a greater affect in environments where one interacts with others, such as the ultimatum game. We examine only one type of optimism-pessimism in our experiment, just as we examine only one environment (ultimatum bargaining) for spillover effects. We feel that our examination of unrelated environments during belief-manipulation and the bargaining experiment is a virtue of this design, to the extent that spillover effects in unrelated environments is a greater challenge to the spillover effect hypothesis. An obvious extension of this research is to examine different types of belief manipulation, in perhaps different environments, and explore potential spillover effects beyond those in bargaining games.

\footnotetext{
${ }^{6}$ We assume, of course, that our subject pool includes both dispositionally optimistic and pessimistic individuals, though we do not gather data on this personality attribute. This highlights the importance of our initial random assignment to the high versus low piece rate task. Such an approach is similar to the mood induction techniques employed by Charness and Levin (2005) and McLeish and Oxoby (2007).
} 
Our data generally support existing research on cognitive dissonance, as well as psychological research on personality disposition. Dispositional optimism-pessimism is, of course, more general than the optimism-pessimism we generate in the lab but, to the extent that one's macro-disposition is the product of micro-beliefs from individual situations, our laboratory generated belief structure is significant. It implies that even psychological constructs are open to laboratory manipulation. This helps make possible more systematic experimental studies of beliefs and their spillover effects, which can highlight the more complete impact of one event on outcomes elsewhere. 


\section{REFERENCES}

Aronson, E. (1992). 'The return of the repressed: dissonance theory makes a comeback', Psychological Inquiry, vol. 3, (March), pp. 303-11.

Aronson, E. (1994). The Social Animal. San Francisco: Freeman Press.

Aronson, E., Carlsmith, J., 1963. "Effect of severity of threat on the valuation of forbidden behavior.” Journal of Abnormal and Social Psychology, 66, 584-588.

Aronson, E., Mills, J., 1959. “The Effect of Severity of Initiation on Liking for a Group.” Journal of Abnormal and Social Psychology 59, 177-181.

Avramov, D., 2002. People, Demography, and Social Exclusion. No. 37 in Population Studies Series. Council of European Publishing, Strasbourg, Belgium.

Axsom, D., Cooper, J., 1985. “Cognitive Dissonance and Psychotherapy: The Role of Effort Justification in Inducing Weight Loss.” Journal of Experimental Social Psychology, 21, 149-160.

Babcock, Linda and George Loewenstein. 1997. "Explaining Bargaining Impasse: The Role of Self-Serving Biases.” Journal of Economic Perspectives, 11(1): 109-26.

Baddeley, A.D. 1968. “A 3 Min Reasoning Test Based on Grammatical Transformation.” Psychonomic Science, 10(10): 341-2.

Barber, Brad and Terrance Odean. 2001. "Boys will be Boys: Gender, Overconfidence, and Common Stock Investment.” Quarterly Journal of Economics, Vol. 116, No. 1, 261-292.

Beauvois, J-L. and R-V Joule. 1996. A Radical Theory of Dissonance. European Monographs in Social Psychology. New York: Taylor and Francis.

Capra, C. M., 2004. "Mood driven distortions in strategic interactions.” American Economic Review Papers and Proceedings, 94 (2), 367-372.

Charness, G. and D. Levin. 2005. "When Optimal Choices Feel Wrong: A Laboratory Study of Bayesian Updating, Complexity, and Psychological Affect.” American Economic Review, 95(4), 1300-1309.

Cooper, J., Worchel, S., 1970. "Role of Undesired Consequences in Arousing Cognitive Dissonance.” Journal of Personality and Social Psychology, 16, 199-206.

Council of Europe (Ed.), 2001. "Promoting the Policy Debate on Social Exclusion from a Comparative Perspective.” Vol. 1 of Trends in Social Cohesion. Council of Europe, Germany. 
Dickinson, David L. 2006. "The Chilling Effect of Optimism: The Case of Final-Offer Arbitration.” Journal of Socio-Economics, 35: 17-30.

Festinger, L. (1957). A Theory of Cognitive Dissonance, Stanford: Stanford University Press.

Festinger, L., Carlsmith, J., 1959. “Cognitive Consequences of Forced Compliance.” Journal of Abnormal and Social Psychology, 59, 203-210.

Fischbacher, U., 2007. "Z-tree: Zurich toolboxfor ready-made economic experiments.” Experimental Economics, 19(2): 171-78.

Glietman, Henry. 1991. Psychology, $3^{\text {rd }}$ edition. New York: Norton.

Goldsmith, Arthur H., Jonathan R. Veum, and William Darity, Jr. 1997. "The Impact of Psychological and Human Capital on Wages.” Economic Inquiry, 35(4): 815-29.

Heinonen, Kati, Katri Raikkonen, and Liisa Keltikangas-Jarvinen. 2005. "Self-esteem in Early and Late Adolescence Predicts Dispositional Optimism-Pessimism in Adulthood: A 21Year Longitudinal Study.” Personality and Individual Differences, 39: 511-21.

Hillman, C. H., Rosengren, K. S., Smith, D. P., March 2004. "Emotion and motivated behavior: Postural adjustments to affective picture viewing.” Biological Psychology, 66 (1), 51-62.

Hoelzl, Erik, and Aldo Rustichini. 2005. "Overconfident: Do You Put Your Money On It?" Economic Journal, 115(April): 305-18.

Holt, Charles. 2007. Markets, Games, \& Strategic Behavior. $1^{\text {st }}$ edition. Pearson Education, Inc.

Konow, James. 2000. "Fair Shares: Accountability and Cognitive Dissonance in Allocation Decisions.” American Economic Review, 90(4): 1072-1091.

Lane, Robert E. 1991. The Market Experience. New York: Cambridge University Press.

Lucas, Richard .E., Ed Diener, and Eunkook M. Suh. 1996. "Discriminant validity of wellbeing meaures." Journal fo Personality and Social Psychology, 71: 616-28.

Lyubomirsky, Sonja. and Laura King. 2005. "The benefits of frequent positive affect: Does happiness lead to success?” Psychological Bulletin, 131(6): 803-55.

McLeish, K.N. and R.J. Oxoby. 2007. “Gender, Affect and Intertemporal Consistency: An Experimental Approach.” IZA Discussion Paper No. 2663.

McLeish, K.N. and R. J. Oxoby. 2007. "Measuring Impatience: Elicited Discount Rates and the Barratt Impulsiveness Scale.” Personality and Individual Differences, 43(3), 553-565..

Montgomery, J. D., 1994. “Revisiting Tally’s Corner.” Rationality and Society, 6 (4), 462-488. 
Odean Terrrance. 1998. "Volume, Volatility, Price, and Profit When All Traders Are Above Average.” Journal of Finance, Vol. LIII, No. 6, 1887-1934.

Oxoby, R. J., 2004. Cognitive dissonance, status, and growth of the underclass. The Economic Journal, 114, 729-749.

Oxoby, R. J. and McLeish, K. N. 2004. "Specific decision and strategy vector methods in ultimatum bargaining: Evidence on the strength of other-regarding behavior.” Economics Letters, 84(3):399-405.

Pyszczynski, Tom, Kathleen Holt, and Jeff Greenberg. 1987. “Depression, Self-Focused Attention, and Expectancies for Positive and Negative Future Life Events for Self and Others.” Journal of Personality and Social Psychology, 52(5): 994-1001.

Rabin, M. and J. Schrag. 1999. "First Impressions Matter: A Model of Confirmatory Bias.” Quarterly Journal of Economics, 114(1): 37 -82.

Rabin, M. 1998. “Psychology and Economics.” Journal of Economic Literature, 36(1): 11 - 46.

Rabin, M. 2002. “Inference By Believers in the Law of Small Numbers.” Quarterly Journal of Economics, 117(3): 775- -816.

Scheier, M. F., and C.S. Carver. 1985. “Optimism, Coping, and Health: Assessment and Implications of Generalized Outcome Expectancies.” Health Psychology, 4: 219-47.

Svenson, Ola. 1981. “Are We All Less Risky and More Skillful Than Our Fellow Drivers?” Acta Psychologica, 94(Feb): 143-48.

Weinstein, N.D., 1980. “Unrealistic Optimism about Future Life Events.” Journal of Personality and Social Psychology, 39(Nov): 806-20. 


\section{Appendix A: Instructions for Experiment 1}

\section{Instructions}

This is an experiment in decision-making. During the experiment you will make a number of decisions which will result in a monetary payoff. You will receive this payment in cash at the end of the experiment. This payment is considered both compensation for the time and the effort you put into making your decisions.

The experiment will proceed in three stages and will last approximately 30 minutes. We ask you to refrain from speaking with one another throughout the course of the experiment. If you have any questions please raise your hand and one the monitors will assist you.

In the first stage of the experiment, you will engage in a task, which is described next.

The task involves reading a short sentence that describes the order of 3 or 4 letters. The short sentence will appear on your computer screen for exactly 3 seconds. Your task is to decide the correct order of the letters based on the description in the short sentence. The sentence will disappear after 3 seconds and another sentence will not reappear for an additional 5 seconds. Before the next sentence appears you are to write down the correct order of the letters (the ones that just disappeared) on your 'LETTER ORDER' sheet. New short sentences will keep appearing, each time for 3 seconds followed by a 5 second break before the next sentence appears. There will be a total of 64 short sentences that will appear before this portion of the experiment is completed.

Because a 3-letter sentences can possibly imply different letter-orders, depending on your interpretation of the sentence, you must determine the proper order of each 3-letter sentence by doing the following. First, determine the order of the first two letters. Then, keep those two letters together and determine where the third letter should go in relation to the first pair of letters. The same rule applies to determining the proper order of each 4-letter sentence. First, determine the order of the first two letters. Then, keep those two letters together and determine where the third letter should go in relation to the first pair of letters. Then, keep those three letters together and determine where the fourth letter should go in relation to the first three letters.

Using this rule, there is only one unique letter-order for any 3- or 4-letter sentence, and it is the letter-order that comes from using this rule that the experimenter will count as the correct response.

Here are some examples of short sentences followed by the correct letter-order. Short sentence

1) $\quad A$ is followed by $D$ is followed by $B$ is preceded by $C$ correct order

2) Z does not precede $\mathrm{X}$ does not follow $\mathrm{Y}$

CADB

$\mathrm{XZY}$

Once you start the main test, sentences will continue to appear for 3 seconds, followed by a 5 second break before the next sentence appears. For each short sentence you are to write down the correct letter order on your 'LETTER ORDER' sheet. You are not allowed to write anything on you letter order sheet other than your letter-order response (e.g., writing down the sentence to think about it later). Any such activity will result in your disqualification from the experiment! Recall that the sentences will continue to reappear for a total of 64 total short sentences. 
Finally, you will be paid today for each short sentence for which you answer the correct letter-order. The amount you will be paid for $\boldsymbol{e}$ ach correct letter-order response will either be $\$ .25$ or $\$ 1.25$. You will not know which payment rate applies in advance of completing this portion of the test, but whatever rate applies will apply for all 64 sentences. In other words, if the payment is $\$ .25$ for each correct letter-order, then we will pay you $\$ .25$ times the number of correct letter-order responses you made (out of all 64 sentences). If the payment rate is $\$ 1.25$, then we will pay you $\$ 1.25$ times the number of correct letter-order responses you made (out of all 64 sentences).

After you have completed this first portion of the experiment you will be asked two questions. First, you will be asked to indicate (on a scale of 1-10) how much you enjoyed the task. Secondly, you will be asked to estimate the number of questions you correctly answered. You will receive a separate monetary payment based on the accuracy of this estimate. Specifically, you will receive a $\$ 5.00$ payment if your estimate is correct, and you will receive a $\$ 3.00$ payment if you estimate is within two of the actual number of letter-orders you correctly indicated.

After you have entered this information you will be informed of the number of questions you correctly answered and your total payoff from the experiment. You will be asked to complete a short questionnaire, after which the experiment will end and you will receive your payment for having participated.

Once we have answered any questions, the experiment will begin. 


\section{Appendix B: Instructions for Experiment 2}

\section{Instructions}

This is an experiment in decision-making. During the experiment you will make a number of decisions which will result in a monetary payoff. You will receive this payment in cash at the end of the experiment. This payment is considered both compensation for the time and the effort you put into making your decisions.

The experiment will proceed in three stages and will last approximately 30 minutes. We ask you to refrain from speaking with one another throughout the course of the experiment. If you have any questions please raise your hand and one the monitors will assist you.

In the first stage of the experiment, you will engage in a task, which is described next.

The task involves reading a short sentence that describes the order of 3 or 4 letters. The short sentence will appear on your computer screen for exactly 3 seconds. Your task is to decide the correct order of the letters based on the description in the short sentence. The sentence will disappear after 3 seconds and another sentence will not reappear for an additional 5 seconds. Before the next sentence appears you are to write down the correct order of the letters (the ones that just disappeared) on your 'LETTER ORDER' sheet. New short sentences will keep appearing for 3 seconds followed by a 5 second break before the next sentence appears. There will be a total of 64 short sentences that will appear before this portion of the experiment is completed.

Because a 3-letter sentence can possibly imply different letter-orders, depending on your interpretation of the sentence, you must determine the proper order of each 3 -letter sentence by doing the following. First, determine the order of the first two letters. Then, keep those two letters together and determine where the third letter should go in relation to the first pair of letters. The same rule applies to determining the proper order of each 4-letter sentence. First, determine the order of the first two letters. Then, keep those two letters together and determine where the third letter should go in relation to the first pair of letters. Then, keep those three letters together and determine where the fourth letter should go in relation to the first three letters.

Using this rule, there is only one unique letter-order for any 3- or 4-letter sentence, and it is the letter-order that comes from using this rule that the experimenter will count as the correct response.

Here are some examples of short sentences followed by the correct letter-order. Short sentence

1) A is followed by $D$ is followed by $B$ is preceded by $C$ correct order

2) Z does not precede $\mathrm{X}$ does not follow $\mathrm{Y}$

CADB

$\mathrm{XZY}$

Once you start the main test, sentences will continue to appear for 3 seconds, followed by a 5 second break before the next sentence appears. For each short sentence you are to write down the correct letter order on your 'LETTER ORDER' sheet. You are not allowed to write anything on you letter order sheet other than your letter-order response (e.g., writing down the sentence to think about it later). Any such activity will result in your disqualification from the experiment! Recall that the sentences will continue to reappear for a total of 64 total short sentences. 
Finally, you will be paid today for each short sentence for which you answer the correct letter-order. The amount you will be paid for each correct letter-order response will either be $\$ .25$ or $\$ .75$. You will not know which payment rate applies in advance of completing this portion of the test, but whatever rate applies will apply for all 64 sentences. In other words, if the payment is $\$ .25$ for each correct letter-order, then we will pay you $\$ .25$ times the number of correct letter-order responses you made (out of all 64 sentences). If the payment rate is $\$ .75$, then we will pay you $\$ .75$ times the number of correct letter-order responses you made (out of all 64 sentences).

After you have completed this first portion of the experiment you will be asked two questions. First, you will be asked to indicate (on a scale of 1-10) how much you enjoyed the task. Secondly, you will be asked to estimate the number of questions you correctly answered. You will receive a separate monetary payment based on the accuracy of this estimate. Specifically, you will receive a $\$ 5.00$ payment if your estimate is correct, and you will receive a $\$ 3.00$ payment if you estimate is within two of the actual number of letter-orders you correctly indicated.

After you have entered this information you will be informed of the number of questions you correctly answered and your total payoff from this part of the experiment.

Next, you will randomly be matched with another person. Eventually, the computer will assign one of you to the role of Proposer and one of you to the role of Responder. Before this random assignment is made, you must indicate what you would do if you were put in either role. In the role of Proposer, you will be asked how much (out of a total of \$10) you wish to allocate to the other person. The amount of money that you keep for yourself will be \$10 minus your allocation to the other person. In the role of Responder, you must indicate for each possible amount allocated to you from the Proposer whether you would accept or reject such an offer. The computer will then randomly assign each person in the pair to the role of Proposer or Responder, and their corresponding choices will be implemented. That is, the person assigned the role of Proposer will have their offer extended to the Responder; the Responder will accept or reject the offer based on the choices made for the relevant amount of the offer. If it turns out that the Responder accepts the Proposer's offer, both people receive the amounts agreed upon. However, if the Responder rejects the Proposer's offer, both people receive nothing.

Your earnings from this portion of the experiment will be added to your previous earnings to make up your final payoff.

You will be asked to complete a short questionnaire, after which the experiment will end and you will receive your payment for having participated.

Once we have answered any questions, the experiment will begin.

\section{Warm-Up Exercises}

1. If you are assigned the role of Proposer and you indicated that you would allocate the other person $\$ 3$, how much will you receive if this offer is accepted?

2. If you are assigned the role of Responder and you are allocated \$6, how much will you receive if you indicated that you would accept a $\$ 6$ offer? How much will you receive if you indicated that you would reject a $\$ 6$ offer? 


\section{Appendix C: Answer sheet used in both experiments}

Please indicate the letter order from each of the numbered short sentences that appears. You are not allowed to write anything else anywhere on this sheet or your instructions.

\begin{tabular}{|c|c|}
\hline $\begin{array}{l}\text { Sentence } \\
\text { number }\end{array}$ & $\begin{array}{l}\text { My letter order } \\
\text { response }\end{array}$ \\
\hline 1) & \\
\hline 2) & \\
\hline 3) & \\
\hline 4) & \\
\hline 5) & \\
\hline 6) & \\
\hline 7) & \\
\hline 8) & \\
\hline 9) & \\
\hline 10) & \\
\hline 11) & \\
\hline 12) & \\
\hline 13) & \\
\hline 14) & \\
\hline 15) & \\
\hline 16) & \\
\hline 17) & \\
\hline 18) & \\
\hline 19) & \\
\hline 20) & \\
\hline 21) & \\
\hline 22) & \\
\hline 23) & \\
\hline 24) & \\
\hline 25) & \\
\hline 26) & \\
\hline 27) & \\
\hline 28) & \\
\hline 29) & \\
\hline 30) & \\
\hline 31) & \\
\hline 32) & \\
\hline
\end{tabular}

\begin{tabular}{|c|c|}
\hline $\begin{array}{l}\text { Sentence } \\
\text { number }\end{array}$ & $\begin{array}{l}\text { My letter order } \\
\text { response }\end{array}$ \\
\hline 33) & \\
\hline 34) & \\
\hline 35) & \\
\hline 36) & \\
\hline 37) & \\
\hline 38) & \\
\hline 39) & \\
\hline 40) & \\
\hline 41) & \\
\hline 42) & \\
\hline 43) & \\
\hline 44) & \\
\hline 45) & \\
\hline 46) & \\
\hline 47) & \\
\hline 48) & \\
\hline 49) & \\
\hline 50) & \\
\hline 51) & \\
\hline 52) & \\
\hline 53) & \\
\hline 54) & \\
\hline 55) & \\
\hline 56) & \\
\hline 57) & \\
\hline 58) & \\
\hline 59) & \\
\hline 60) & \\
\hline 61) & \\
\hline 62) & \\
\hline 63) & \\
\hline 64) & \\
\hline
\end{tabular}

